\title{
Prioritization of patients in ICU: composite approach of multiple-criteria decision-making and discrete event simulation
}

\author{
Afsaneh Davodabadi ${ }^{1}$, Behrooz Daneshian¹, Saber Saati², Shabnam Razavyan³ \\ ${ }^{1}$ Department of Mathematics, Central Tehran Branch, Islamic Azad University, Tehran, Iran \\ ${ }^{2}$ Department of Mathematics, North Tehran Branch, Islamic Azad University, Tehran, Iran \\ ${ }^{3}$ Department of Mathematics, South Tehran Branch, Islamic Azad University, Tehran, Iran
}

How to cite: Davodabadi, A., Daneshian, B., Saati, S. et al. (2021), “Prioritization of patients in ICU: composite approach of multiple-criteria decision-making and discrete event simulation", Brazilian Journal of Operations \& Production Management, Vol. 18, No. 1, 2021975. https://doi.org/10.14488/BJOPM.2021.008

\section{ABSTRACT}

Goal: This article aims to present a systematic approach to improve the resource allocation and human queues prioritization patterns.

Design / Methodology / Approach: To achieve such a purpose, effective criteria using a fuzzy-Delphi method, and subject-related researchers' views were obtained. Utilizing the Analytic Network Process method, the weights of each criterion was measured. Then, considering the established weights and using a fuzzy-TOPSIS method, a prioritization system via Discrete Event Simulation was developed.

Results: Results indicate that the established approach properly improved the performance of the prioritization system in terms of resources and facilities allocation in neurology's ICUs.

Limitations of the investigation: A drawback of this research can be in states of emergency which limits the options at hand and the criteria proposed may set a drawback on the aim of the study.

Practical implications: The results show that the proposed model can modify patient entry based on multiple criteria in terms of productivity and social justice in the patient queuing strategy.

Originality / Value: The contribution of this research is threefold: the literature has been reviewed to conclude the criteria concerning decisions around ICUs, the concluded criteria filtered through an expert panel which can be relied based on the method, a real application of the steps proposed is presented which allows comparing the accuracy and efficiency of the decisions made in the hospitals.

Keywords: Hospital Equipment Allocation; Fuzzy set theory; FANP; FTOPSIS; Discrete Event Simulation.

\section{INTRODUCTION}

Today, the issue of human queues management has emerged as vital to most or all aspects of human life. Before reducing waiting times in queues, the way the services are managed has a significant impact on customer satisfaction; thus, managers seek to improve their performance (Zhou et al., 2018). The proper use of resources to meet the needs of the clients has turned out to be vital, which calls for a systematic decision-making process. This is especially important in the healthcare system due to the sensitivity and unique characteristics of service recipients. Long waiting times for patients in the queue and lack of proper management to prioritize patients for treatment can lead the situation to become critical or cause irretrievable issues. Therefore, given all the constraints, healthcare

Financial support: None.

Conflict of interest: The authors have no conflict of interest to declare.

Corresponding author: a.davodabadi66@yahoo.com

Received: 22 May 2020.

Accepted: 23 Nov 2020.

Editor: Osvaldo L. G. Quelhas and Julio Vieira Neto. 
managers should always decide how to use the resources and facilities to improve and maintain the patient's health (Pegoraro et al., 2020; Ahsan et al., 2019).

Given this and resource constraint, designing a pattern to prioritize patients in ICU is vital (Louriz et al., 2012). Researches have detected some limited instructions, providing all the signs related to the hospitalization of patients in ICU (Sprung et al., 2013). These instructions are not always useful. In some hospitals, especially in developing countries with limited resources, it is not possible to obey such guidance (Mery and Kahn, 2013). Therefore, deciding to hospitalize in ICU is up to a doctor's opinion and not according to standard instruction (Adhikari et al., 2010). Hence, designing a pattern for entrance and admission prioritization in ICU appears to be very important. ICU is a unit for patients whose survival functions are impaired and thus need further technology, intense medication, close follow-up, and care to make them able to continue their normal functions. The number of hospitals and consequently that of beds in such units is increasing across the world; however, it seems that demand for the unit in hospitals is more than its supply (Mullins and Pines, 2014).

On the other side of this problem, it is well known that prioritizing patients for services in a hospital is a complex process with uncertainty and ambiguity. Using trial and error methods in the health system to gain experience and achieve the best results has always been disapproved by professionals and managers in the field of health organizations. In this regard, human queues in the health system can be studied using research science in operations. Multi-criteria decision-making makes it is possible to model the criteria to queue the patients, and the relative importance of each criterion can be found, thereby minimizing the risk and cost of ongoing processes of serving the patient and executives.

A report on mortalities has indicated that half of all such fatal accidents have occurred as a result of delayed treatment in the emergency section (Richardson et al., 2009). Delay in transferring patients from the emergency department to inpatient wards increases the length of hospital stay by $12.4 \%$ and hospitalization costs by $11 \%$ (Huang et al., 2010). On the other hand, numerous studies over the past few decades have shown that proper triage of injured patients has reduced mortality and improved resource utilization.

Considering the aforementioned remarks, this research aims to establish a pattern for entrance and servicing the patients in ICU. To do this, the previous research is reviewed, then effective criteria for the entrance of patients to ICUs are identified, and at last, identified criteria are confirmed by other respected experts using a fuzzy-Delphi method. In the next stage utilizing the fuzzy-ANP method, the identified fuzzy criteria are weighted. Besides, using the most important established criteria, the prioritization of patients is done via a fuzzy-TOPSIS method. Finally, the prioritization system using Discrete Event Simulation is analyzed. In the next section, the literature is reviewed. In the third section, the research methods, including fuzzy-Delphi, fuzzy-ANP, fuzzyTOPSIS, and simulation approach, are discussed. Forth section deals with interpreting the results and findings, and in the end, the conclusion is provided.

\section{LITERATURE REVIEW}

Long waiting time not only results in a decrease in the effectiveness but also makes patients conditions more acute; for instance, they may get permanent disabilities (Globerman et al., 2013). Prioritization of patients in waiting lists and their access to variable treatments is one of the most important issues in hygiene institutions. Prioritization is a complicated multi-criteria decision-making process. Scoring systems as decision-making gadgets are designed to guide the surgeons and doctors (Globerman et al., 2013). Still, there is a need to develop proper prioritization gadgets to rank patients in waiting lists. Thus, the management of waiting lists and proper prioritization of patients can reduce these unfortunate outcomes (Sun et al., 2018). The gadgets have advantages including the specification of waiting lists and individuals in a 
service waiting list which helps them in decision-making and performing new tasks (Sampietro-Colom et al., 2008).

The scoring system was introduced in the 1990s; however, as prioritization and scoring patients were performed by the influence of arbitrary personal opinions, unpleasant and deadly consequences were obtained, and this led to heavy criticism (Fraser et al., 1993).

Four major problems with prioritization stated by Sun et al. (2018) are as follows:

1. Prioritization of patients is a complicated process, which is always followed by uncertainty and ambiguity.

2. Stability and justice must be considered as one of the prioritization criteria.

3. There is double-sided dependence between some prioritization criteria.

4. Possible dangers should be considered since the patients feeling may become acute.

The development of prioritization instruments has been the strategy followed by some countries like New Zealand, Canada, and the United Kingdom among others to manage waiting lists (MacCormick et al., 2003). It involves the use of priority scoring tools which are means of generating a score (MacCormick et al., 2003). The development of these instruments is a lengthy and costly process, and in general, has been focused on specific diseases. Although evidence is not conclusive, one might expect that establishing common criteria for all types of medical procedures might simplify the implementation process and allow for a comparable tool to be used across different procedures (Allepuz et al., 2009). In the case of ICUs, the prioritization approaches are now static, and the patient condition is assessed by adding them to their list. Some level of uncertainty and disharmony must be considered in medical science and clinical methods (Sadegh-Zadeh, 2015).

Despite the importance of ICU in a hospital and the need to utilize scientific approaches for entrance and admission of patients, there is not much literature on the prioritization of patients in it. Bailey (1952) conducts the first known work to reduce client waiting times, in which he balances patient and physician waiting times through mathematical queuing models to minimize waiting time. The shift system he proposes is known as Bailey's Law. The basis of this Law is to appoint two people at the beginning of a doctor's appointment. Subsequent appointments are given one by one at a constant interval equal to the average examination time. The results of the experiments show that this shifting method successfully increases efficiency.

Since the 1950s and early 1960s, by increasing the number of patients admitted to the emergency section of hospitals, experts have found that there is a need for a method to distinguish patients in need of urgent care from those with lesser problems. This prompts emergency department officials to seek appropriate applicable action to expedite the identification and differentiation of injured and critically ill patients from those who have no urgent and chronic complaints (Gilboy et al., 2005). Therefore, the use of a triage system to prioritize emergency section patients is suggested as the appropriate solution to this problem.

In all studies done on a queue control, the aim is often to maximize profit or social welfare and fairness. A common method of prioritizing is to give absolute priority to customers in the queue according to the fixed-priority (Hassin et al., 2009). In the research done by Alexander et al. (2012), some of the priority queues in the amusement park have been investigated, where the volume of requests is the same; however, one can be prioritized by paying more. According to the results, the existence of such a priority causes dissatisfaction and a sense of unfairness in the customers present in the main queue and also hurts referral.

Another type of priority is the relative, where the priority given to one class depends on the state variables in the other classes as well. In research by Haviv and van der Wal (2007), the average waiting time in a single server queue with the Poisson input distribution and service time is discussed. In the research by Hassin et al. (2009) and Sun et al. (2009), relative 
priority allocation is discussed, and it shows that by allocating relative priority, the cost in the system is a function of customer waiting time in queue. It decreases compared to the FIFO state.

Creemers and Lambrecht (2007) explain how the queue model offers a great tool for analyzing and improving the performance of healthcare systems. Researchers have used queuing systems to analyze health systems, such as hospitals (Green et al., 2006), pharmaceutical industry) Viswanadham and Narahari (2001), and emergency services) Singer and Donoso (2008).

Accurate and rapid triage of patients is the key to perform successfully in the emergency section; if an inappropriate triage level is chosen based on misinterpretation or neglect of patient variables and triage criteria, the nurse will have a triage error (Lehmann et al., 2009). The triage error can be in the form of placing patients lower than the actual status, which may lead to waiting and worsening their conditions, or classifying the patients in a higher level than the actual situation, over triage or severe triage; undertriage is a delay in the diagnosis and treatment of severely injured patients, which may result in death) Dehli et al., 2011).

To achieve the subject of "safety in providing patient care," triage needs to be minimized while keeping the severe triage at a low level for optimal use of resources (Lehmann et al., 2009). In a study by Creemers et al. (2012), a method for prioritizing patients in the surgical queue is presented. The results show a reduction in the expected waiting time for patients. Chalgham et al. (2019) have introduced a new approach to rank hospital units, which can accommodate emergency patients when the emergency section is full.

The research gap after the literature review could be summarized as the lack of a systematic decision-making process in entrance and admission of the patients to ICUs which could be addressed by utilizing decision theory practices. To consider all the aspects, criteria concluded in the literature and suggested by experts are used as the metrics to develop a system of decision-making. Given this, the criteria are screened using a fuzzy-Delphi method using experts' opinions. Another weakness of prior studies is the absence of a numerical approach to have rating results assessed clear and cut. In this study, in addition to the use of weighting and fuzzy ranking methods, results of prioritization patterns, as well as all of their details, can be exported from the simulation system output. As in the real world, most of the criteria have a stochastic nature. In this study, due to their high ability to analyze the accidental and complicated systems, Discrete Event Simulation methods are used to consider the mentioned characteristic and become close to reality.

\section{METHODOLOGY}

Regarding the subject of this research, the utilized approach is the hybrid of multi-criteria decision-making and simulation. Figure 1 presents the research stages.

1) Gathering effective criteria for the ranking of patients.

2) Screening criteria using a fuzzy-Delphi method.

3) Weighting the prioritization criteria using a fuzzy-ANP method.

4) Prioritizing patient groups using a fuzzy-TOPSIS method.

5) Simulating the system's current status using discrete event simulation (ED).

6) Validating the simulated model.

7) Simulating the prioritized system using discrete event simulation (ED).

8) Analyzing the results. 


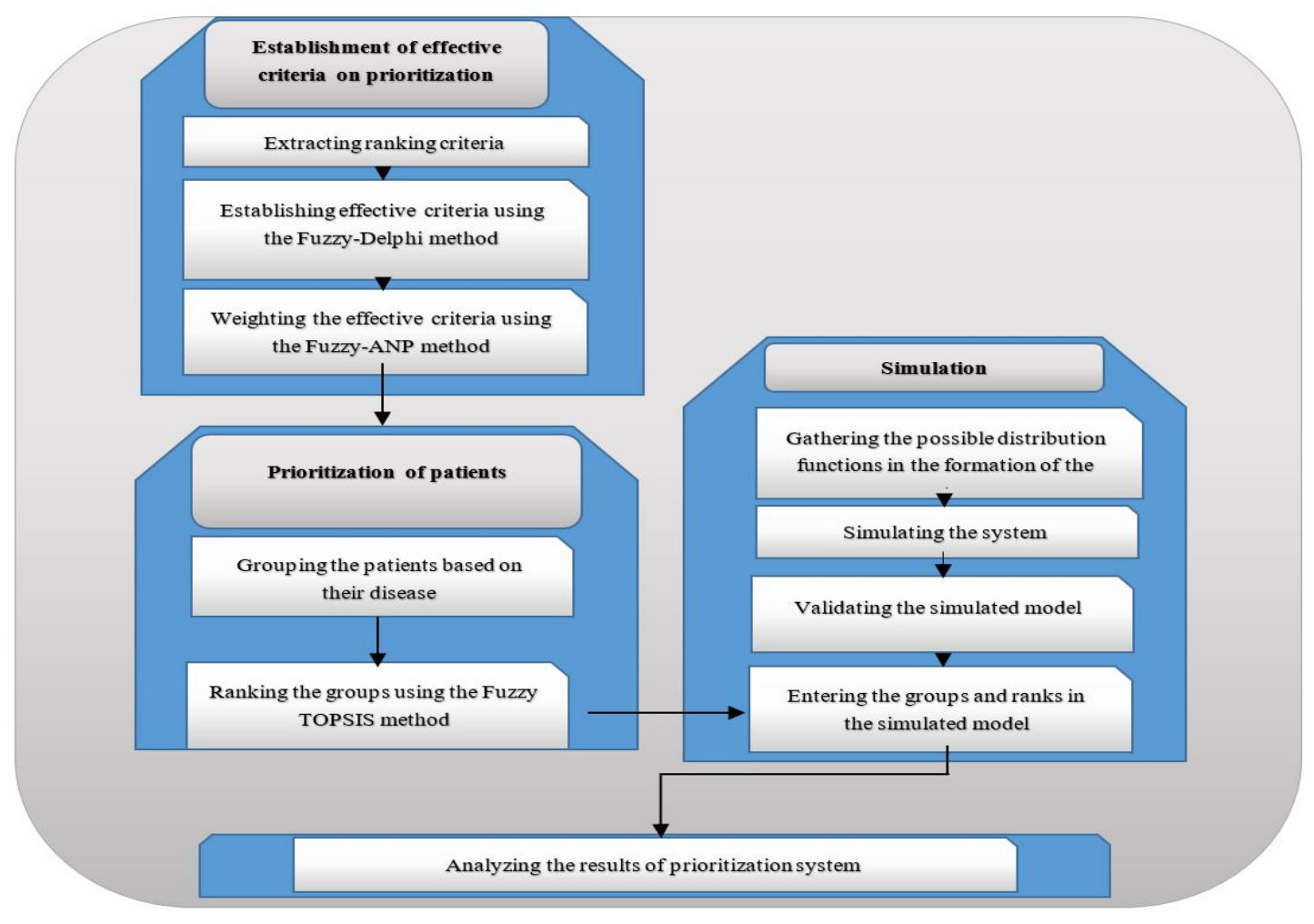

Figure 1: The diagram of research stages (Authors)

\subsection{Fuzzy Logic}

Individuals' judgment about priorities to estimate values are often unclear, and dedication of a number to it is not possible, thus fuzzy logic is useful for unclear and uncertain problems. The fuzzy theory was first presented by Zadeh (1965) to adjust the uncertainty of people understanding of models. Fuzzy numbers are shown by "on top of the number. Triangular fuzzy numbers are shown in Figure 2.

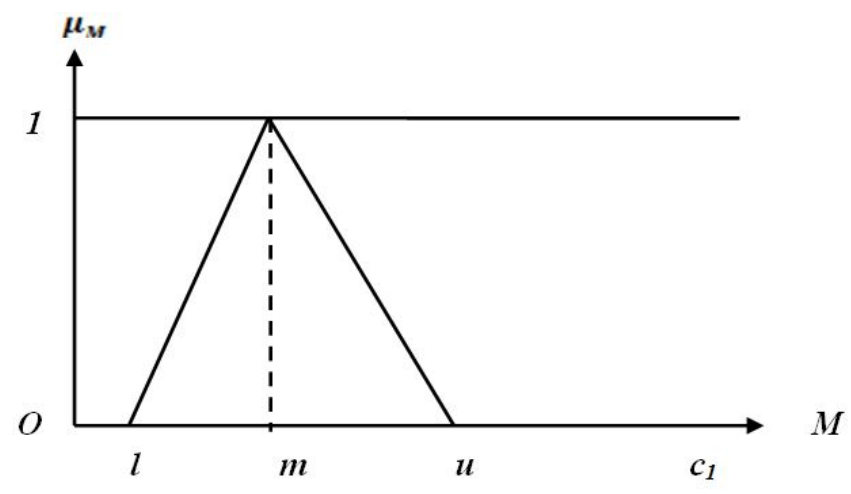

Figure 2: Presentaion of triangle fuzzy number (Adapted from Zadeh, 1965)

Triangular fuzzy numbers are demonstrated by $(l, m, u)$. These parameters are denoted as the least possible prospective content, possible prospective content, and the most possible prospective content, respectively. The membership function of a triangular fuzzy number is demonstrated as a linear function, which is defined on its left and right side as following Equation 1: 


$$
\mu_{\tilde{M}}(x)=\left\{\begin{array}{cc}
0 & x<l \\
\frac{x-l}{m-l} & l \leq x \leq m \\
\frac{u-x}{u-m} & m \leq x \leq u \\
0 & x>u
\end{array}\right.
$$

\section{2. Fuzzy-Delphi Method}

The Delphi method was first introduced in Round Company in 1963. It is a geodesic method based on experts' views; it has three main features as following: unnamed response, repeated controlled feedback, and finally, statistical group response (Hsu et al., 2010). This technic is a disciplined method to gather and harmonize the award group judgments of specialists about a question or a special topic. In many real situations, judgments of specialists cannot be stated and interpreted as measurable contents. In other words, data and certain numbers due to ambiguity and uncertainty are not enough for modeling the real-world systems in the decision maker's view. Thus, to overcome this situation, the theory of fuzzy is a suitable method to remove ambiguity and uncertainty in the decision-making process (Zadeh, 1965). Therefore, in this research, the fuzzy-Delphi method is used to screen and confirm the criteria. Delphi method steps are as following (Bouzon et al., 2016):

First step: identifying the criteria by reviewing the theoretical bases of research overall.

Second step: gathering the decision maker's opinions. In this step, after identifying the criteria, the decision-making group, including specialists with the related research subject, is formed, and a questionnaire is sent to them to evaluate the correlation of identified criteria with the original subject of research. To do this, lingual variables, including Very low, Low, Moderate, High, Very high, are used to state the importance of each criterion. There is a vast range of fuzzy numbers, including triangular and trapezoidal fuzzy numbers. In this research, triangular fuzzy numbers are used due to their simplicity. They are presented as $\tilde{M}=(l, m, u)$, standing for smallest, most possible, and biggest possible values.

Third step: validating important criteria. This is done by comparing the gained value of every criterion and threshold $\mathrm{d} \tilde{S}$. Using the mean value of criteria as the threshold content is one of the most trustable methods (Hsu et al., 2010). To do this, initially, the content of a triangular fuzzy number of $\tilde{a}_{i j}=\left(l_{i j}, m_{i j}, n_{i j}\right) ; i=1,2, \ldots, n, j=1,2, \ldots, m$ is calculated by researcher's view. In this relation, $i$ denotes the expert person, and $j$ stands for decision-making criteria. $\tilde{a}_{i j}$ is the gained fuzzy content of each decision-maker person; to calculate the opinion of $\mathrm{n}$ respondent, mean fuzzy of them are calculated. Thus, the fuzzy numbers of each criterion should be calculated. The triangular fuzzy number of $\tilde{a}_{j}=\left(l_{j}, m_{j}, u_{j}\right)$, where $\widetilde{a_{j}}$ is the mean fuzzy value of criteria for each criterion, is calculated through the following Equations (Hsu et al., 2010):

$l_{j}=\min \left(l_{i j}\right)$

$m_{j}=\left(\prod_{i=1}^{n} m_{i j}\right)^{\frac{1}{n}}$

$u_{j}=\max \left(u_{i j}\right)$

Moreover, the calculated mean fuzzy content by Equation 5 is defuzzied using the centroid of the area method (Chang et al., 2011). 
Crisp $=\frac{l+2 m+u}{4}$

After calculating the mentioned contents, if the defuzzied content is $\tilde{a}_{j} \geq \tilde{S}$, the criterion is approved and will be entered to the main stage of decision-making; however, if the defuzzied content is $\tilde{a}_{j}<\tilde{S}$, the criterion will be rejected.

\section{3. Geometric Mean Buckley Method}

The geometric mean Buckley method is utilized to calculate relative weights in pairwise fuzzy scales (Hsieh et al., 2004). The stages of this method are as below:

Assume $\tilde{P}_{i j}$ is a set of decision-maker preferences about a criterion dependent on other criteria. Matrix of pairwise comparison scales is as follows:

$$
\tilde{\boldsymbol{A}}=\left[\begin{array}{ccc}
1 & \tilde{P}_{12} & \tilde{P}_{1 n} \\
\tilde{P}_{21} & 1 & \tilde{P}_{2 n} \\
\tilde{P}_{n 1} & \tilde{P}_{n 2} & 1
\end{array}\right]
$$

In this Equation, $\mathrm{n}$ stands for the number of related elements in each row. The fuzzy weight of each criterion in the matrix is obtained using the geometric mean Buckley method. The geometric mean of fuzzy's comparing value for $i$ on each criterion is obtained through Equation 7.

$\tilde{r}_{i}=\left(\prod_{j=1}^{n} \tilde{P}_{i j}\right)^{1 / n} \quad i=1,2, \ldots, n$

Then, the fuzzy weight of ith criterion is shown by a triangular fuzzy number Equation 8.

$w_{i}=r_{i}\left(r_{1}+r_{2}+\ldots+r_{m}\right)^{-1}$

After calculating fuzzy weight factors, using the below formula, weights are defuzzied and then normalized.

$w_{\text {crisp }}=\frac{l+2 m+u}{4}$

\section{4. Fuzzy ANP Method}

ANP method uses a pairwise comparison matrix to rate and rank the preferences in which certain numbers are entrance data. However, in the case of ambiguity, this matrix cannot be used. To solve this problem, researchers have presented a model that uses the ANP method in a fuzzy environment. The difference of the presented model with the conventional ANP is in the extraction of important weights from the fuzzy pairwise comparison matrix. Other steps are the same as in the conventional ANP method.

In the fuzzy-ANP method, the relative importance of each pair of elements and preferences of decision-makers is shown by triangular fuzzy numbers. By the pairwise comparison, fuzzy judgments matrix of $A^{\prime}$ forms in which $\tilde{a}_{i j}=\left(l_{i j}, m_{i j}, u_{i j}\right)$ tells the importance of compared criteria, the importance of $i$ relating to $j$ (Uygun et al., 2015), as in Equation 10. 
$\tilde{A}=\left(\begin{array}{ccc}\tilde{a}_{11} & \cdots & \tilde{a}_{1 n} \\ \vdots & \ddots & \vdots \\ \tilde{a}_{m 1} & \cdots & \tilde{a}_{m n}\end{array}\right)$

To establish a priority vector gained from each pairwise comparison matrix, various methods, such as Developed Interoperation and Logarithmic Least Squares, exist, one of which can be taken to calculate it. In the ANP method, a supermatrix is used to illustrate interaction and dependencies between two dimensions of decision-making, the establishment of criteria dependent importance, and prioritization of the question alternatives. A supermatrix (Table 1) is, indeed, a partitioned matrix that, in every part of it, the relation between two ties or levels of a decision in all the decision-making questions is shown in which $C$ denotes the tie and e denotes the elements in the tie. $W$ vectors in this matrix are weight vectors gained from pairwise comparison of tie elements with each other, as shown in Table 1.

Table 1: $W$ matrix

\begin{tabular}{|c|c|c|c|c|c|}
\hline \multirow{2}{*}{\multicolumn{2}{|c|}{ Criteria }} & \multirow{3}{*}{$\begin{array}{c}C_{1} \\
e_{11} e_{12} \ldots e_{1 m 1} \\
W_{11}\end{array}$} & \multirow{3}{*}{$\begin{array}{c}C_{2} \\
e_{21} e_{22} \ldots e_{2 m 2} \\
W_{12}\end{array}$} & \multirow{3}{*}{$\begin{array}{l}\cdots \\
\cdots \\
\cdots\end{array}$} & \multirow{3}{*}{$\begin{array}{c}C_{n} \\
e_{n 1} e_{n 2} \ldots e_{n m n} \\
W_{l n}\end{array}$} \\
\hline & & & & & \\
\hline$C_{1}$ & $e_{11} e_{12} \vdots e_{1 m 1}$ & & & & \\
\hline $\mathrm{C}_{2}$ & $e_{21} e_{22} \vdots e_{2 m 2}$ & $W_{21}$ & $W_{22}$ & $\ldots$ & $W_{2 n}$ \\
\hline$\vdots$ & $\vdots$ & $\vdots$ & $\vdots$ & $\ldots$ & $\vdots$ \\
\hline$C_{n}$ & $e_{n 1} e_{n 2} \vdots e_{n m n}$ & $W_{n 1}$ & $W_{n 2}$ & $\ldots$ & $W_{n n}$ \\
\hline
\end{tabular}

In the initial supermatrix, every weight of columns is divided into the overall sum of weights in that column. Gained matrixes are called weighted/stochastic supermatrix that, indeed, are obtained by normalizing the initial supermatrix. Using the stochastic supermatrix, the final supermatrix is calculated, and the weight of each criterion is obtained. To calculate the final supermatrix, the weighted/stochastic supermatrix should be raised to the large enough power until the weights converge and remain stable, as in Equation 11.

$W=\lim _{K \rightarrow \infty} W^{2 k+1}$

$K$ is a natural number, and its content can be raised arbitrarily to reach convergence. In other words, all the weights in a row or a column become the same.

\section{5. Fuzzy TOPSIS}

TOPSIS, as a well-known classic ranking method, is another useful tool in decision-making to rank the alternatives. TOPSIS steps are as follows (Jahanshahloo et al., 2006):

The first step is the normalization of the fuzzy decision matrix. Then, Equation 12 is utilized to normalize the decision matrix. By using this Equation, each value in each column is normalized by the maximum value of the same column.

$\tilde{r}_{i j}=\frac{\tilde{\chi}_{i j}}{\max \left(\tilde{\chi}_{i j}\right)}$

Where in Equation 12, $i=1,2, \ldots, m$ and $j=1,2, \ldots, n$, experts define different weights. Then, the weighted normalized decision matrix is calculated by multiplying the matrix of weights in the normalized matrix. The matrix of weights and the weighted normalized matrix with fuzzy values are formed as follows: 
$\left[\tilde{W}_{i, j}\right]=\left[\begin{array}{cccc}\tilde{W}_{1,1} & \cdots & 0 & 0 \\ 0 & \tilde{W}_{2,2} & 0 & 0 \\ \cdots & \cdots & \cdots & \cdots \\ 0 & \cdots & 0 & \tilde{W}_{n, n}\end{array}\right]$

$\tilde{\vartheta}_{\mathrm{ij}}=\left[\tilde{\mathrm{r}}_{\mathrm{i}, \mathrm{j}}\right] \times\left[\tilde{\mathrm{w}}_{\mathrm{j}, \mathrm{j}}\right]=\left[\begin{array}{ccccc}\tilde{\mathrm{r}}_{1,1} \times \tilde{\mathrm{w}}_{1} & \cdots & \tilde{\mathrm{r}}_{1, \mathrm{n}-1} \times \tilde{\mathrm{w}}_{\mathrm{n}-1} & \tilde{\mathrm{r}}_{1, \mathrm{n}} \times \tilde{\mathrm{w}}_{\mathrm{n}} \\ \tilde{\mathrm{r}}_{2,1} \times \tilde{\mathrm{w}}_{1} & \cdots & \tilde{\mathrm{r}}_{2, \mathrm{n}-1} \times \tilde{\mathrm{w}}_{\mathrm{n}-1} & \tilde{\mathrm{r}}_{2, \mathrm{n}} \times \tilde{\mathrm{w}}_{\mathrm{n}} \\ \ldots & \ldots & & \ldots & \cdots \\ \tilde{\mathrm{r}}_{\mathrm{m}, 1} \times \tilde{\mathrm{w}}_{1} & \cdots & \tilde{\mathrm{r}}_{\mathrm{m}, \mathrm{n}-1} \times \tilde{\mathrm{w}}_{\mathrm{n}-1} & \tilde{\mathrm{r}}_{\mathrm{m}, \mathrm{n}} \times \tilde{\mathrm{w}}_{\mathrm{n}}\end{array}\right]$

$i=1,2, \ldots, m$ and $j=1,2, \ldots, n$.

Then, ideal and anti-ideal points can be defined by Equations 15 and 16.

$\left.\tilde{A}^{+}=\left(\tilde{\vartheta}_{1}^{+}, \cdots \tilde{\vartheta}_{n}^{+}\right)=\left\{\max \tilde{\vartheta}_{i j} \mid(i=1,2, \cdots, n), j=1,2, \cdots, n\right)\right\}$

$\left.\tilde{A}^{-}=\left(\tilde{\vartheta}_{1}^{-}, \cdots \tilde{\vartheta}_{n}^{-}\right)=\left\{\max \tilde{\vartheta}_{i j} \mid(i=1,2, \cdots, n), j=1,2, \cdots, n\right)\right\}$

The total measure of the distance between each alternative and the anti-ideal points can be obtained using Equations 17 to 19:

$$
\begin{aligned}
& d\left(\tilde{M}_{i}, \tilde{M}_{j}\right)=\sqrt{\frac{1}{3}\left[\left(l_{i}-l_{j}\right)^{2}+\left(m_{i}-m_{j}\right)^{2}+\left(u_{i}-u_{j}\right)^{2}\right]} \\
& \tilde{s}_{i}^{+}=\sqrt{\sum_{j=1}^{n} d\left(\tilde{\vartheta}_{i j}, \tilde{\vartheta}_{i j}^{+}\right)} i=1,2, \ldots, m \\
& \tilde{s}_{i}^{-}=\sqrt{\sum_{j=1}^{n} d\left(\tilde{\vartheta}_{i j}, \tilde{\vartheta}_{i j}^{-}\right)} i=1,2, \ldots, m
\end{aligned}
$$

where $d$ is the distance between two fuzzy numbers.

The closeness coefficient for each alternative is calculated using Equation 20, which is used to rank each alternative. The highest value of the closeness coefficient factor is the farthest from the anti-ideal point.

$\tilde{C}_{i}^{*}=\frac{\tilde{s}_{i}^{-}}{\tilde{s}_{i}^{-}+\tilde{s}_{i}^{+}} i=1,2, \ldots, m$

In the final step, alternatives are ranked based on the value of $\tilde{C}_{i}^{*}$.

\section{6. Discrete-Event Simulation}

Simulation is adopted to emulate the current state of any process (Al-Refaie and Li, 2011). Simulation can be used as an effective analysis technique to create, retain, appraise, or improve a system or process. Simulation within healthcare has been used for a long time to solve bottlenecks related to healthcare in total. Discrete Event Simulation represents and enables the modeling of the complicated and stochastic streams of patients that are usually dealt with in healthcare clinics (Jacobson et al., 2006). Furthermore, the most studied 
simulation technique for healthcare improvement in the literature is Discrete-Event Simulation, which is followed by Monte Carlo Simulation and System Dynamics (SD) (Young et al., 2009). It seems that computer simulation, compared to most traditional statistical methods, is a good alternative with less time and costs. Among different simulation methods, discrete-event simulation is one of the most used ones in healthcare are and different parts of treatment, such as the emergency. In this research, Enterprise Dynamics software is used to model simulation. ED was officially introduced by In control Simulation Solution, a Dutch company, for the first time in 2003. In contrast to other software, like Arena that is process-oriented, this software is an object-oriented simulation, which is combined with the event-driven method.

\section{7. Verification and Validation of Simulation}

The next stage in simulation is to assure the accuracy and validity of the simulated model. The simulated model should have a real-world like function to extend its results to the reality, (Equation 21). Steps of validation are shown in Figure 3:

$\left\{\begin{array}{l}H_{0}: u_{A}=u_{B} \\ H_{l}: u_{A} \neq u_{B}\end{array}\right.$

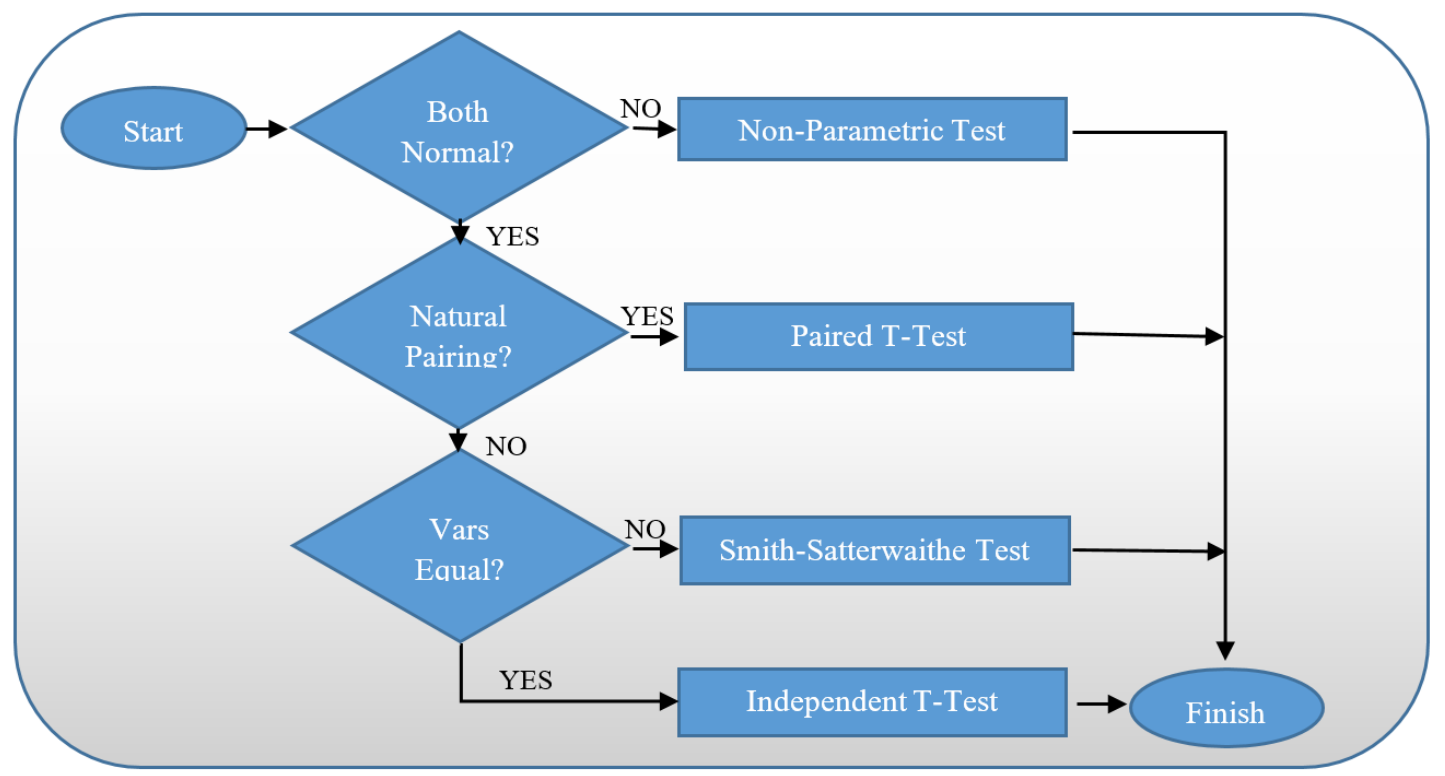

Figure 3: Validation graphic of the simulated model (Chung, 2003)

First, it should be determined that the data collected from real and simulated models have normal and abnormal distribution. If the data were not normal, a non-parametric test or Kolmogorov-Smirnov test would be used. If the data were normal, statistical parametric tests would be used. That is, if the data have a paired mode, data are not independent but dependent on other sample data. If the data do not have a paired mode and equal variances, the Smith-atterwrite test is used; otherwise, an independent-T test is used.

\section{RESULTS AND DISCUSSION}

In this research, patients in the ICU of neurosurgery in Tehran X Hospital were chosen as the study system. There were 14 beds in this section. To sort the entered patients to ICU, data regarding characteristics of patients in NCCU were collected; then, data related to the entrance time of patients using the hospital information system were extracted. Six types of patients, 
including Trauma, Brain tumor, Cerebrovascular, Cerebral hemorrhage, Hydrocephalus, and Spine surgery, had been accepted in this section contain.

\section{1. Choosing the Prioritization Criteria}

After investigating the research background and extracting effective criteria in the prioritization of patients, some other effective criteria are presented, and a tree of decisionmaking for prioritization criteria of patients in ICU is illustrated, as in Figure 4.

\section{Prioritization of patients in waiting list}

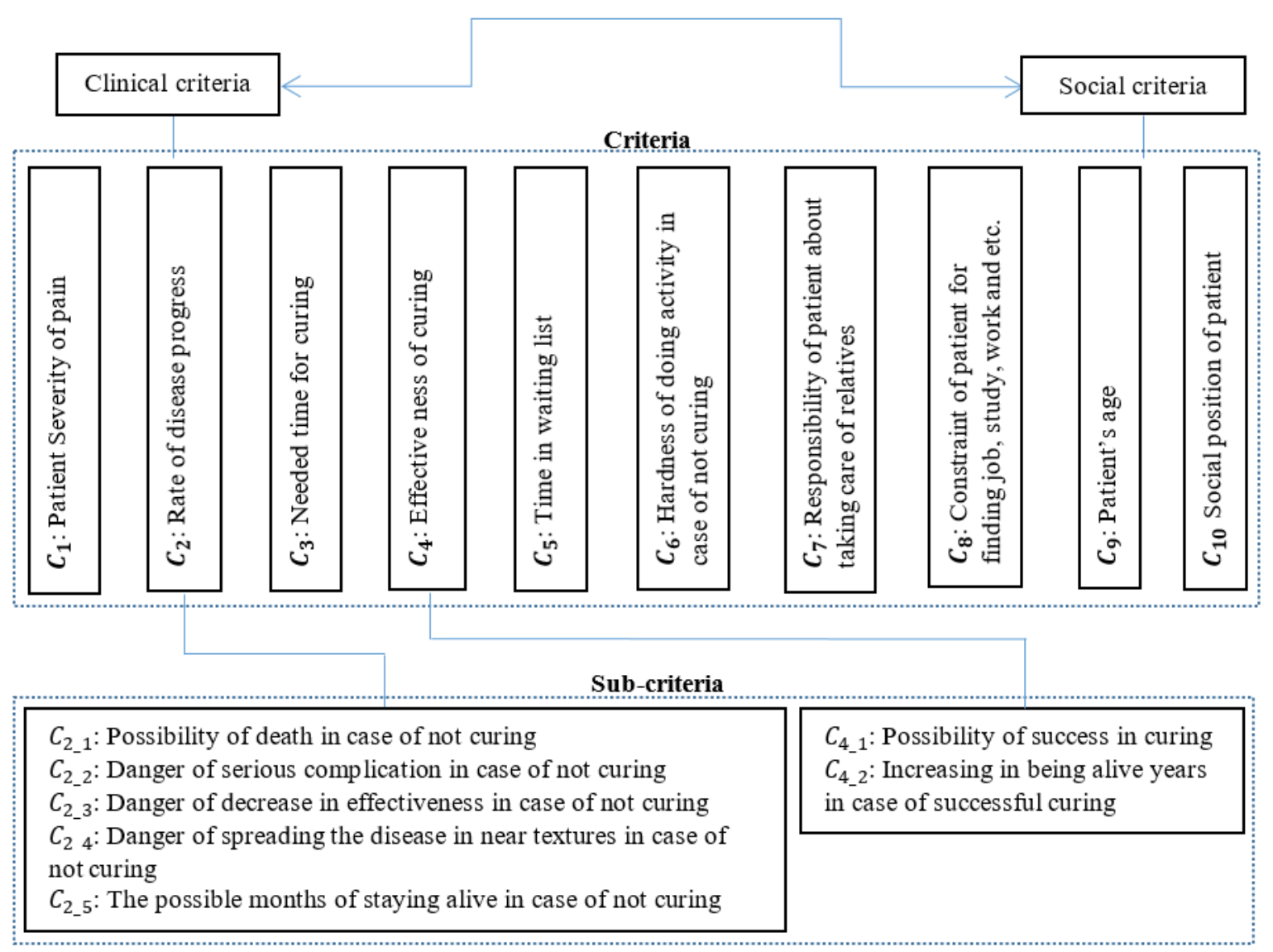

Figure 4: Extracted criteria for prioritization of patients (Authors)

\section{2. Screening Effectiveness of Criteria Using Fuzzy-Delphi Method}

Choosing a cycle of experts is one of the most important parts of the Delphi method. Awareness of the mentioned group about the subject is a good guarantee for high-quality results in Delphi. Thus, a Delphi cycle member in research is chosen based on specialty and not on a random selection process. A researcher chooses the Delphi cycle regarding their awareness of the subject. Therefore, a list of 12 doctors and hospital employees, who have close contact with health system management, are selected. After collecting 12 filled questionnaires, the defuzzied content of each question is calculated; then, using these, outputs are interpreted. In this study, according to experts' opinion, criteria with more than a mean spectrum of 3 , as their defuzzied content, are considered as important criteria, and those with a mean spectrum less than 3 are considered as less important criteria. Therefore, given the aforementioned remarks and Table 2, criteria of social position are selected as less important effective criteria and thus are omitted. 
Table 2: Output of the Delphi method

\begin{tabular}{|c|c|c|c|c|c|c|}
\hline \multirow{2}{*}{$\begin{array}{l}\text { Question } \\
\text { number }\end{array}$} & \multicolumn{3}{|c|}{$\begin{array}{c}\text { Fuzzy value of each } \\
\text { question }\end{array}$} & \multirow{2}{*}{$\begin{array}{c}\text { Defuzzied content of each } \\
\text { question }\end{array}$} & \multirow{2}{*}{$\begin{array}{l}\text { Question's } \\
\text { condition }\end{array}$} & \multirow{2}{*}{$\begin{array}{l}\text { Consensus } \\
\text { percentage }\end{array}$} \\
\hline & $L$ & $M$ & $U$ & & & \\
\hline$C_{1}$ & 4 & 5 & 5 & 4.614 & proved & 75 \\
\hline$C_{2}$ & 4 & 4 & 5 & 4.404 & proved & 66.67 \\
\hline$C_{2}{ }_{2}$ & 4 & 4 & 5 & 4.364 & proved & 75 \\
\hline$C_{2 \_}$ & 4 & 4 & 5 & 4.364 & proved & 75 \\
\hline$C_{2 \_3}$ & 5 & 5 & 5 & 5 & proved & 100 \\
\hline$C_{2 \_4}$ & 5 & 5 & 5 & 5 & proved & 100 \\
\hline$C_{2-5}$ & 4 & 4 & 5 & 4.404 & proved & 66.67 \\
\hline$C_{3}$ & 4 & 4 & 5 & 4.404 & proved & 66.67 \\
\hline$C_{4}$ & 4 & 4 & 5 & 4.364 & proved & 75 \\
\hline$C_{4 \_1}$ & 3 & 3 & 4 & 3.361 & proved & 75 \\
\hline$C_{4 \_2}$ & 2 & 3 & 4 & 3.058 & proved & 66.67 \\
\hline$C_{5}$ & 3 & 3 & 3 & 3 & proved & 100 \\
\hline$C_{6}$ & 3 & 3 & 3 & 3 & proved & 100 \\
\hline$C_{7}$ & 4 & 4 & 5 & 4.287 & proved & 91.67 \\
\hline$C_{8}$ & 2 & 3 & 4 & 3.021 & proved & 75 \\
\hline$C_{9}$ & 3 & 3 & 4 & 3.4 & proved & 66.67 \\
\hline$C_{10}$ & 1 & 1 & 1 & 1 & rejected & 100 \\
\hline
\end{tabular}

Given the remarks mentioned earlier in the topic literature, the weight of the researcher's criteria using the fuzzy-ANP method is presented. Initially, as can be seen in Table 3, internal relations of criteria and sub-criteria are established by experts.

Table 3: Internal relations of criteria and sub-criteria

\begin{tabular}{|c|c|}
\hline \multicolumn{2}{|c|}{ Relations of criteria and sub-criteria } \\
\hline & GOAL \\
\hline$C_{1}, C_{2}, C_{3}, C_{4}, C_{5}, C_{6}, C_{7}, C_{8}, C_{9}$ & $C_{1}$ \\
\hline$C_{1}, C_{3}, C_{4}, C_{6}$ & \multirow{2}{*}{$C_{2}$} \\
\hline$C_{2 \_}, C_{2 \_}, C_{2-3}, C_{2 \_}, C_{2 \_} 5$ & \\
\hline & $C_{3}$ \\
\hline$C_{2}$ & \multirow{2}{*}{$C_{4}$} \\
\hline$C_{4 \_}, C_{4 \_}$ & \\
\hline$C_{2}$ & $C_{5}$ \\
\hline$C_{1}, C_{7}, C_{8}$ & $C_{6}$ \\
\hline$C_{6}, C_{8}, C_{9}$ & $C_{7}$ \\
\hline \multirow[t]{2}{*}{$C_{1}, C_{6}, C_{7}, C_{9}$} & $C_{8}$ \\
\hline & $C_{9}$ \\
\hline$C_{2 \_}, C_{2-3}, C_{2-4}, C_{2-5}$ & \multirow{2}{*}{$C_{2} 1$} \\
\hline$C_{2}, C_{4}{ }_{-}$ & \\
\hline$C_{2-1}, C_{2}{ }_{-3}, C_{2 \_} 4, C_{2} \_5$ & \multirow{2}{*}{$\mathrm{C}_{2 \_}{ }_{2}$} \\
\hline$C_{2}, C_{4}{ }_{-}$ & \\
\hline$C_{2-1}, C_{2-2}, C_{2-4}, C_{2-5}$ & $\mathrm{C}_{2}{ }_{3} 3$ \\
\hline
\end{tabular}




\section{Relations of criteria and sub-criteria}

\section{GOAL}

\begin{tabular}{|c|c|}
\hline$C_{2}, C_{4}{ }_{-}$ & \\
\hline$C_{2 \_}{ }^{\prime}, C_{2{ }_{-} 2}, C_{2 \_}{ }_{3}, C_{2 \_} 5$ & \multirow{2}{*}{$\mathrm{C}_{2}{ }_{-} 4$} \\
\hline$C_{2}, C_{4 \_} 1$ & \\
\hline$C_{2 \_}, C_{2-2}, C_{2 \_}, C_{2}{ }_{-}$ & \multirow{2}{*}{$C_{2-5}$} \\
\hline$C_{2}, C_{4-1}$ & \\
\hline 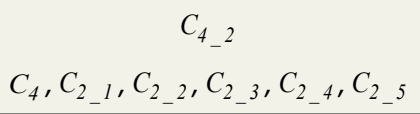 & $C_{4 \_1}$ \\
\hline$C_{4}, C_{2}{ }_{-}, C_{2}{ }_{2}, C_{2}{ }_{3}, C_{2}{ }_{4}, C_{2}-5$ & $C_{4}{ }_{-2}$ \\
\hline
\end{tabular}

To calculate related weights of the researcher's criteria, initially, a questionnaire of pairwise comparison criteria considering their internal relations is formed. After forming the questionnaire, they are passed to decision-makers to complete it. In this research, to calculate the weight in a pairwise comparison, lingual phrases and triangular fuzzy members stipulated in Table 4 are used.

Table 4: Lingual phrases and fuzzy numbers for the weight of criteria

\begin{tabular}{ccccc}
\hline \multirow{2}{*}{ NO } & Lingual Variables & \multicolumn{2}{c}{ Fuzzy Numbers } \\
\cline { 2 - 5 } & Equally important & M & U \\
\hline $\mathbf{1}$ & Equal to partly more important & 1 & 1 & 1 \\
\hline $\mathbf{2}$ & Partly important & 1 & 2 & 3 \\
\hline $\mathbf{3}$ & Partly important to highly important & 2 & 3 & 4 \\
\hline $\mathbf{4}$ & Highly important & 3 & 4 & 5 \\
\hline $\mathbf{5}$ & Highly to very highly important & 4 & 5 & 6 \\
\hline $\mathbf{6}$ & Very highly important & 5 & 6 & 7 \\
\hline $\mathbf{7}$ & Very highly to totally important & 6 & 7 & 8 \\
\hline $\mathbf{8}$ & Totally important & 7 & 8 & 9 \\
\hline $\mathbf{9}$ & & 8 & 9 & 10 \\
\hline
\end{tabular}

By filling out the pairwise comparison questionnaire using convertible fuzzy numbers table, judgments of experts are altered to suitable triangular fuzzy numbers. After forming the network structure of research, performing the fuzzy pairwise comparison, and obtaining weights, the supermatrix of question should be formed. The first supermatrix of question is uneven supermatrix, as can be seen in Table 5.

Table 5: The first supermatrix

\begin{tabular}{|c|c|c|c|c|c|c|c|c|c|c|c|c|c|c|c|c|c|c|}
\hline & & \multicolumn{5}{|c|}{$C_{2}$} & \multicolumn{2}{|c|}{$C_{4}$} & \multicolumn{9}{|c|}{ criteria } & \multirow{2}{*}{ Goal } \\
\hline & & $C_{2 \_l}$ & $C_{2 \_} 2$ & $C_{2 \_} 3$ & $C_{2 \_4}$ & $C_{2 \_5}$ & $C_{4 \_} 1$ & $C_{4}{ }_{-2}$ & $C_{1}$ & $C_{2}$ & $C_{3}$ & $C_{4}$ & $C_{5}$ & $C_{6}$ & $C_{7}$ & $C_{8}$ & $\overline{C_{9}}$ & \\
\hline \multirow{4}{*}{$C_{2}$} & $C_{2 \_} 1$ & 0 & 0.705107 & 0.4272 & 0.675363 & 0.633667 & 0.527365 & 0.53016 & 0 & 0.623194 & 0 & 0 & 0 & 0 & 0 & 0 & 0 & 0 \\
\hline & $C_{2 \_} 2$ & 0.42548 & 0 & 0.24551 & 0.139939 & 0.121561 & 0.113719 & 0.11357 & 0 & 0.113489 & 0 & 0 & 0 & 0 & 0 & 0 & 0 & 0 \\
\hline & $C_{2 \_} 3$ & 0.16971 & 0.119211 & 0 & 0.129309 & 0.122041 & 0.199048 & 0.19295 & 0 & 0.115519 & 0 & 0 & 0 & 0 & 0 & 0 & 0 & 0 \\
\hline & $C_{2} 5$ & 0.04546 & 0.055311 & 0.0437 & 0.055389 & 0 & 0.04738 & 0.04761 & 0 & 0.03684 & 0 & 0 & 0 & 0 & 0 & 0 & 0 & 0 \\
\hline
\end{tabular}




\begin{tabular}{|c|c|c|c|c|c|c|c|c|c|c|c|c|c|c|c|c|c|c|}
\hline & & \multicolumn{5}{|c|}{$C_{2}$} & \multicolumn{2}{|c|}{$C_{4}$} & \multicolumn{9}{|c|}{ criteria } & \multirow{2}{*}{ Goal } \\
\hline & & $C_{2 \_} 1$ & $C_{2 \_}{ }_{2}$ & $C_{2 \_} 3$ & $C_{2 \_4}$ & $C_{2 \_5}$ & $C_{4 \_1}$ & $C_{4 \_2}$ & $C_{1}$ & $C_{2}$ & $C_{3}$ & $C_{4}$ & $C_{5}$ & $C_{6}$ & $C_{7}$ & $C_{8}$ & $C_{9}$ & \\
\hline \multirow{2}{*}{$C_{4}$} & $C_{4 \_1}$ & 1 & 1 & 1 & 1 & 1 & 0 & 0 & 0 & 0 & 0 & 0.83539 & 0 & 0 & 0 & 0 & 0 & 0 \\
\hline & $C_{4}{ }_{-2}$ & 0 & 0 & 0 & 0 & 0 & 1 & 0 & 0 & 0 & 0 & 0.16461 & 0 & 0 & 0 & 0 & 0 & 0 \\
\hline \multirow{9}{*}{ Criteria } & $C_{1}$ & 0 & 0 & 0 & 0 & 0 & 0 & 0 & 0 & 0.151134 & 0 & 0 & 0 & 0.14995 & 0.14995 & 0.13501 & 0 & 0.0517 \\
\hline & $C_{2}$ & 1 & 1 & 1 & 1 & 1 & 0 & 0 & 0 & 0 & 0 & 1 & 1 & 0 & 0 & 0 & 0 & 0.3419 \\
\hline & $C_{3}$ & 0 & 0 & 0 & 0 & 0 & 0 & 0 & 0 & 0.302267 & 0 & 0 & 0 & 0 & 0 & 0 & 0 & 0.0393 \\
\hline & $C_{4}$ & 0 & 0 & 0 & 0 & 0 & 1 & 1 & 0 & 0.390428 & 0 & 0 & 0 & 0 & 0 & 0 & 0 & 0.3052 \\
\hline & $C_{5}$ & 0 & 0 & 0 & 0 & 0 & 0 & 0 & 1 & 0 & 0 & 0 & 0 & 0 & 0 & 0 & 0 & 0.0411 \\
\hline & $C_{6}$ & 0 & 0 & 0 & 0 & 0 & 0 & 0 & 0 & 0.156171 & 0 & 0 & 0 & 0 & 0.42971 & 0.56993 & 0 & 0.0837 \\
\hline & $C_{7}$ & 0 & 0 & 0 & 0 & 0 & 0 & 0 & 0 & 0 & 0 & 0 & 0 & 0.42971 & 0 & 0.18076 & 0 & 0.0346 \\
\hline & $C_{8}$ & 0 & 0 & 0 & 0 & 0 & 0 & 0 & 0 & 0 & 0 & 0 & 0 & 0.33305 & 0.33305 & 0 & 0 & 0.078 \\
\hline & $C_{9}$ & 0 & 0 & 0 & 0 & 0 & 0 & 0 & 0 & 0 & 0 & 0 & 0 & 0.08729 & 0.08729 & 0.1143 & 0 & 0.0245 \\
\hline \multicolumn{2}{|c|}{ Goal } & 0 & 0 & 0 & 0 & 0 & 0 & 0 & 0 & 0 & 0 & 0 & 0 & 0 & 0 & 0 & 0 & 0 \\
\hline
\end{tabular}

Since the sum of some columns in the matrix is not equal to 1 , it cannot be stated that the final effect of the considered control criterion has been truly shown. Thus, the weight of each element in a column cluster of supermatrix should be multiplied to a vector of relative importance in that cluster. Hence, the sum of elements in all columns of supermatrix becomes equal to 1 . The obtained supermatrix is called an even supermatrix. Table 6 shows the even supermatrix of this study.

Table 6: Even supermatrix

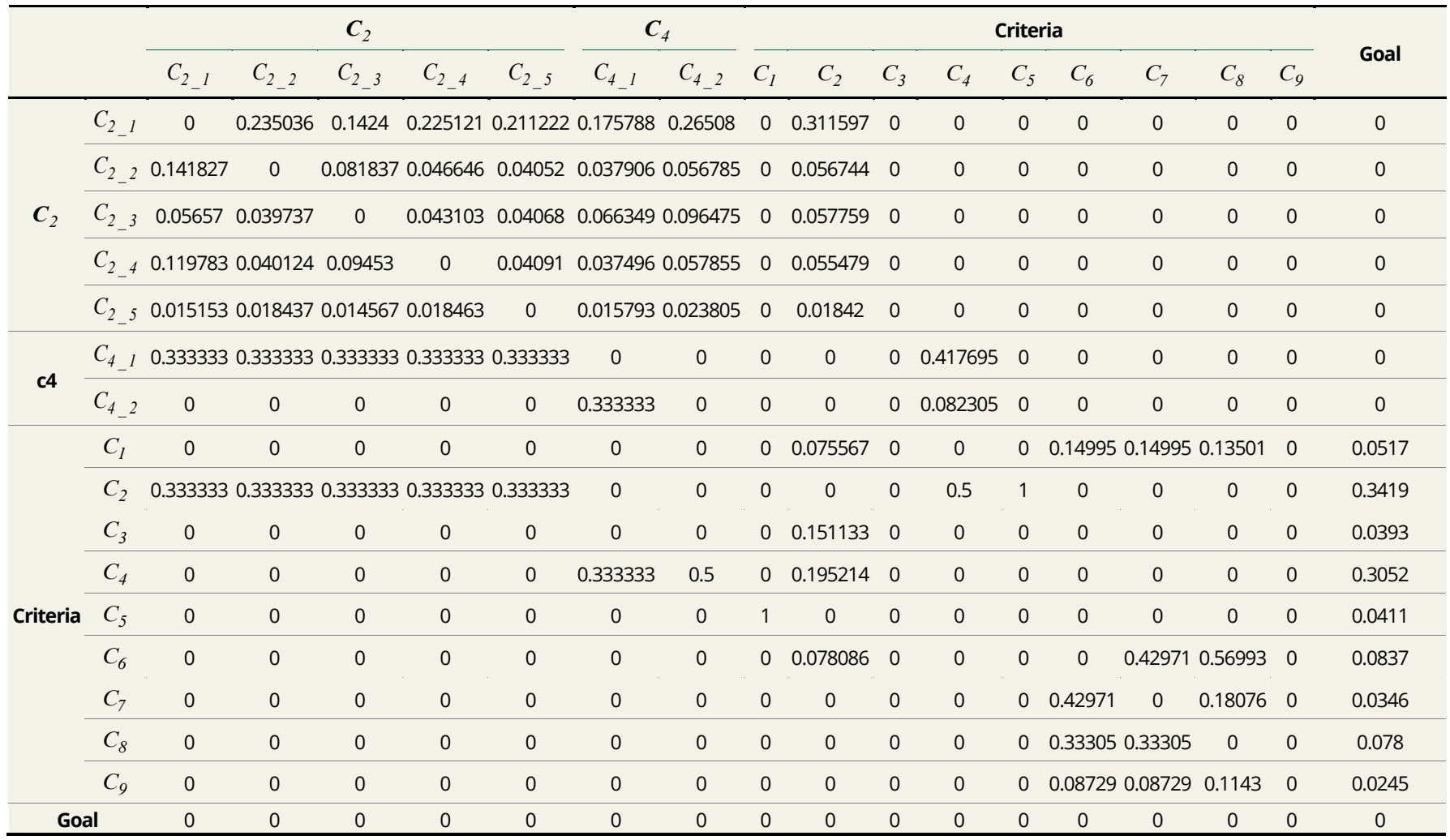

After forming the even matrix, it should be powered by an arbitrary very big number to obtain the long-time relative effect of each element of even matrix on each other. By doing this, all the elements of the supermatrix columns become equal. This matrix is called the boundary supermatrix. In the boundary supermatrix, the weights of all model's agents are identified. In this matrix, shown numbers in each row demonstrate the weight of the corresponding agent of that. To use these weights in interpreting and ranking, they must be 
altered to normal weights. Normalized and boundary weights of research agents are illustrated in Table 7.

Table 7: Boundary and normalized agents of the study

\begin{tabular}{ccc}
\hline Criteria & Limiting weight & Normalized weight \\
\hline$C_{1}$ & 0.026791 & 0.05462 \\
\hline$C_{2}$ & 0.195285 & 0.39811 \\
\hline$C_{3}$ & 0.030682 & 0.06255 \\
$C_{4}$ & 0.127153 & 0.25921 \\
\hline$C_{5}$ & 0.027852 & 0.05678 \\
\hline$C_{6}$ & 0.036189 & 0.07377 \\
\hline$C_{7}$ & 0.019809 & 0.04038 \\
\hline$C_{8}$ & 0.019388 & 0.03952 \\
\hline$C_{9}$ & 0.007385 & 0.01506 \\
\hline$C_{2 \_1}$ & 0.140944 & 0.48725 \\
\hline$C_{2 \_} 2$ & 0.048537 & 0.16779 \\
\hline$C_{2 \_3}$ & 0.041802 & 0.14451 \\
\hline$C_{2 \_4}$ & 0.045434 & 0.15707 \\
\hline$C_{2 \_5}$ & 0.01255 & 0.04339 \\
\hline$C_{4 \_1}$ & 0.155451 & 0.70596 \\
\hline$C_{4 \_2}$ & 0.064747 & 0.29404 \\
\hline
\end{tabular}

After calculating the weight of criteria, patient categories are prioritized using the fuzzy-TOPSIS method; for this purpose, the matrix of the question decision should be formed for six types of studied patients. In this research, the condition of each patient type related to each research criterion is evaluated by 13 decision-makers using lingual variables and fuzzy spectrum stipulated in Table 8 . Its results have been presented in Table 9.

Table 8: Fuzzy variables of TOPSIS method

\begin{tabular}{cc}
\hline Lingual phrase & Stipulated fuzzy number \\
\hline Totally low & $(0,0,1)$ \\
\hline Very low & $(0,1,3)$ \\
Low & $(1,3,5)$ \\
Equal & $(3,5,7)$ \\
High & $(5,7,9)$ \\
Very high & $(7,9,10)$ \\
Totally high & $(9,9,10)$ \\
\hline
\end{tabular}

Table 9: TOPSIS method

\begin{tabular}{ccccccc}
\hline Option of criteria & Brain tumor & Trauma & Spine surgery & Cerebrovascular & Hydrocephalus & $\begin{array}{c}\text { Cerebral } \\
\text { hemorrhage }\end{array}$ \\
\hline $\begin{array}{c}\text { Intensity of patient's } \\
\text { pain }\end{array}$ & $(2.84,4.84,6.846)$ & $(3,5,7)$ & $(9,10,10)$ & $(5,7,9)$ & $(7,9,10)$ & $(3,5,7)$ \\
\hline
\end{tabular}




\begin{tabular}{|c|c|c|c|c|c|c|}
\hline $\begin{array}{l}\text { Danger of death in case } \\
\text { of delay }\end{array}$ & $(9,10,10)$ & $(9,10,10)$ & $(2.84,4.84,6.84)$ & $(8.69,9.76,9.92)$ & $(8.38,9.53,9.84)$ & $(9,10,10)$ \\
\hline $\begin{array}{c}\text { Danger of serious } \\
\text { complication in case of } \\
\text { delay }\end{array}$ & $(9,10,10)$ & $(9,10,10)$ & $(5,7,9)$ & $(5,7,9)$ & $(8.69,9.76,9.9)$ & $(9,10,10)$ \\
\hline $\begin{array}{c}\text { Danger of reduction in } \\
\text { effectiveness in case of } \\
\text { delay }\end{array}$ & $(9,10,10)$ & $(9,10,10)$ & $(0.92,2.76,4.69)$ & $(5,7,9)$ & $(8.69,9.76,9.92)$ & $(9,10,10)$ \\
\hline $\begin{array}{l}\text { Danger of spreading } \\
\text { the disease in near } \\
\text { textures in case of not } \\
\text { curing }\end{array}$ & $(9,10,10)$ & $(0,0,1)$ & $(0,0,1)$ & $(0,0,1)$ & $(0,0,1)$ & $(0,0,1)$ \\
\hline $\begin{array}{l}\text { Possibility of surviving } \\
\text { in case of delay(waiting } \\
\text { list) }\end{array}$ & $(1,3,5)$ & $(0,0,1)$ & $(5.30,7.23,9.07)$ & $(1,3,5)$ & $(0,0,1)$ & $(0,0,1)$ \\
\hline Needed time for curing & $(8.84,9.92,10)$ & $(6.07,7.92,9.38)$ & $(5,7,9)$ & $(3.31,5.30,7.3)$ & $(2.84,4.84,6.84)$ & $(5.30,7.23,9.07)$ \\
\hline $\begin{array}{l}\text { Possibility of success in } \\
\text { curing }\end{array}$ & $(3,5,7)$ & $(5.15,7.15,9.07$ & $(7,9,10)$ & $(5,7,9)$ & $(0.077,1.15,3.15)$ & $(1,3,5)$ \\
\hline $\begin{array}{l}\text { Increase in curing } \\
\text { period }\end{array}$ & $(5.31,7.23,9.07)$ & $(7.15,9.07,10)$ & $(3,5,7)$ & $(3,5,7)$ & $(1,3,5)$ & $(5,7,9)$ \\
\hline Waiting list period & $(3,5,7)$ & $(3,5,7)$ & $(3,5,7)$ & $(3,5,7)$ & $(3,5,7)$ & $(3,5,7)$ \\
\hline $\begin{array}{l}\text { Hardness of doing } \\
\text { activity in case of not } \\
\text { curing }\end{array}$ & $(5,7,8.92)$ & $(8.84,9.92,10)$ & $(5.61,7.46,9.15)$ & $(5.15,7.15,9.07)$ & $(8.84,9.92,10)$ & $(9,10,10)$ \\
\hline $\begin{array}{l}\text { Responsibility of patent } \\
\text { in taking care of } \\
\text { relatives }\end{array}$ & $(3,5,7)$ & $(3,5,7)$ & $(3,5,7)$ & $(3,5,7)$ & $(3,5,7)$ & $(3,5,7)$ \\
\hline $\begin{array}{l}\text { Constraint in finding } \\
\text { job, study or work in } \\
\text { case of not curing }\end{array}$ & $(5.15,7.15,9.07)$ & $(3.15,5.15,7.15)$ & $(5.76,7.61,9.23)$ & $(5,7,9)$ & $(6.84,8.84,9.92)$ & $(9,10,10)$ \\
\hline Patients' age & $(3,5,7)$ & $(3,5,7)$ & $(3,5,7)$ & $(3,5,7)$ & $(3,5,7)$ & $(3,5,7)$ \\
\hline
\end{tabular}

After all stages of the fuzzy-TOPSIS method regarding research literature, six types of patients based on multiple criteria and their weight are established in which Trauma, Brain tumor, Cerebrovascular, Cerebral hemorrhage, Hydrocephalus, and Spine surgery form the priorities of neurology unit, respectively, as can be seen in Table 10.

Table 10: Result of TOPSIS method

\begin{tabular}{ccc}
\hline Patient classification & Result & Priority \\
\hline Trauma & 0.642941 & 1 \\
\hline Brain tumor & 0.632826 & 2 \\
\hline Cerebrovascular & 0.577112 & 3 \\
\hline Cerebral hemorrhage & 0.56346 & 4 \\
\hline Hydrocephalus & 0.517121 & 5 \\
\hline Spine surgery & 0.491971 & 6 \\
\hline
\end{tabular}

\section{3. System Simulation}

To create a simulated model of patients in NCCU, distribution of data and the period of residency are calculated, and a model for 14 beds of NCCU by FIFO order for the patient entrance by ED software is simulated. Figure 5 shows the overall view of the model. 


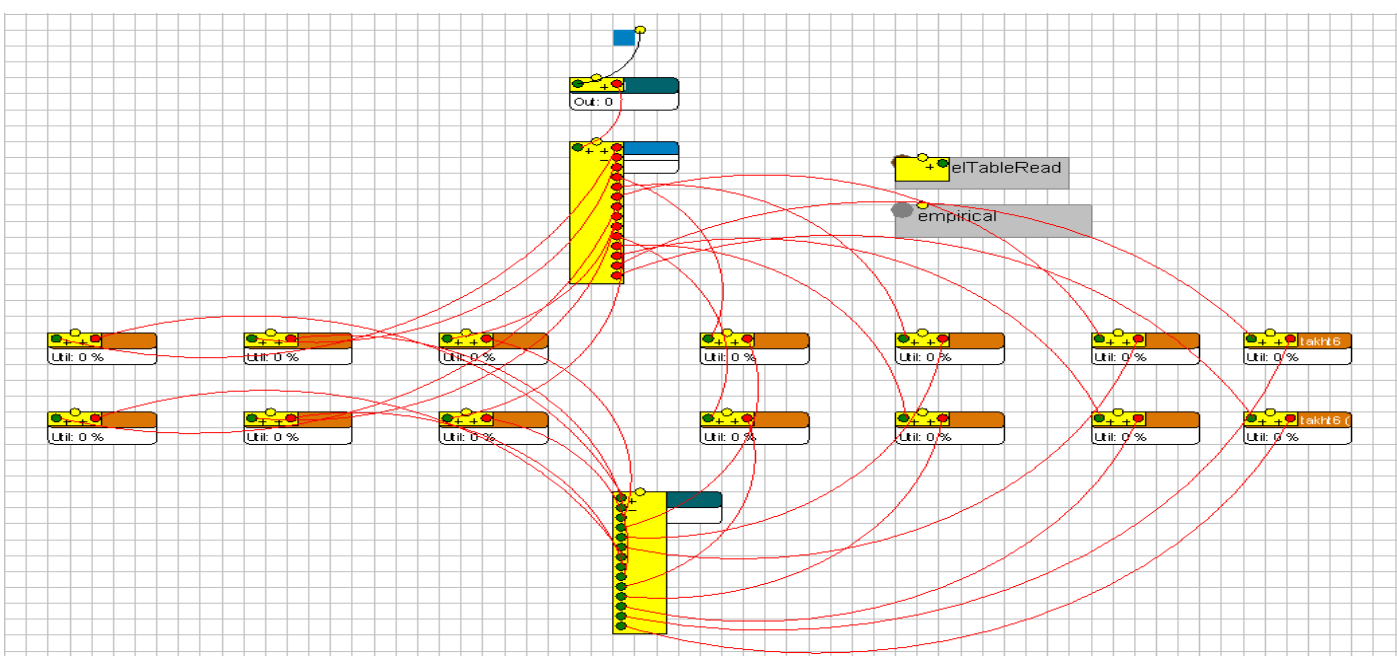

Figure 5: Simulated model of ICU (Authors)

To determine the validity of the simulated model, the number of discharged patients would be studied. For this, the simulated model is implemented in the last ten months and compared with ten months ago data. According to Chang chart (Figure 3), the assumption should be assessed first to make sure that the two samples are normal (Table 11).

Table 11: Outputs from the simulated model and real information

\begin{tabular}{ccccccccccc}
\hline Simulated models' output $\left(\boldsymbol{C}_{1}\right)$ & $\mathbf{7 2}$ & $\mathbf{8 3}$ & $\mathbf{7 1}$ & $\mathbf{7 4}$ & $\mathbf{7 1}$ & $\mathbf{6 6}$ & $\mathbf{7 0}$ & $\mathbf{6 7}$ & $\mathbf{7 8}$ & $\mathbf{7 0}$ \\
\hline Real data $\left(\boldsymbol{C}_{2}\right)$ & 93 & 80 & 68 & 67 & 71 & 70 & 79 & 71 & 73 & 75 \\
\hline
\end{tabular}
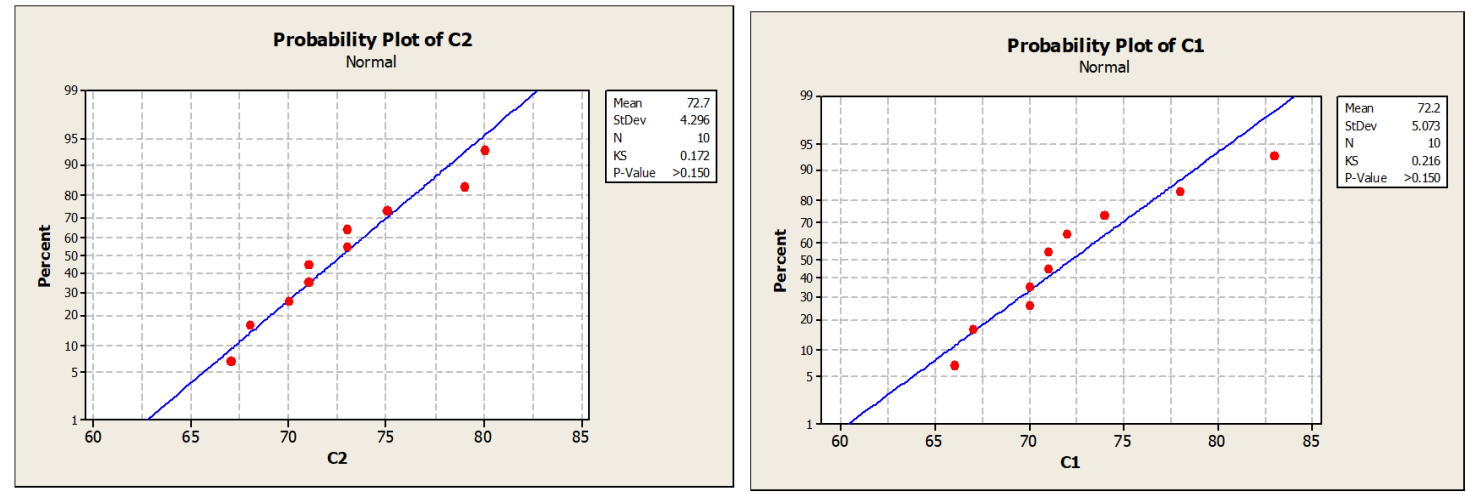

Figure 6: P-values for resulted outputs from the simulated model and real information

According to Figure 6, the p-values for the simulated model and real data, it can be understood that both societies follow the normal distribution. Noticing that the data are paired, a paired T-test is used for checking the validity of the model; see Table 12.

Table 12: Paired T-Test

\begin{tabular}{c}
\hline Paired T-Test and $\boldsymbol{C}_{\boldsymbol{I}}: \boldsymbol{C}_{\boldsymbol{1}} ; \boldsymbol{C}_{2}$ \\
\hline Paired T for $C_{1}-C_{2}$ \\
\hline N Mean StDev SE Mean \\
\hline$C_{1} \quad 1072.205 .071 .60$ \\
$C_{2} \quad 1072.704 .301 .36$ \\
\hline
\end{tabular}


Difference $10-0.505 .041 .59$

95\% $C_{I}$ for mean difference: $(-4.10 ; 3.10)$

$T$-Test of mean difference $=0$ (vs not $=0):$-Value $=-0.31$-Value $=0.761$

According to results, it can be understood that the two societies are equal, and the model has good validity.

\section{4. Simulation Results}

After the validation of the model, it is necessary to investigate the obtained results of the simulated model. Thus, the simulated model is run for 320 times, and then results are presented in Table 13.

Table 13: Simulation result

\begin{tabular}{ccc}
\hline & Observation period:2592000 \\
\hline & $\begin{array}{c}\text { Warmup period:86400 } \\
\text { Number of observations:320 }\end{array}$ \\
\hline & Simulation method: Separate runs & \\
\hline Atom & FIFO OUTPUT & PRIORITY OUTPUT \\
Brain tumor & 10.6 & 15 \\
Cerebral hemorrhage & 11.25 & 8.1 \\
\hline Cerebrovascular & 8.99 & 13 \\
\hline Hydrocephalus & 6.51 & 4.8 \\
\hline Spine surgery & 21.5 & 15 \\
\hline Trauma & 13.99 & 17 \\
\hline
\end{tabular}

\section{RESULTS DEBATE}

Based on the results of the simulated model in FIFO mode and also after applying the prioritization, it is clear that according to the set criteria, the composition of patients should be changed to improve system efficiency.

As in the research literature, the importance of patient prioritization criteria was emphasized. In order to prioritize patients, it is very important that the main criteria are clearly defined (Abbasgholizadeh Rahimi et al., 2016).

Accordingly, in this study, the main and sub-criteria were determined and the importance of each was determined using fuzzy ANP of which the rate of disease progress and effectiveness of curing ranks higher due to the life emergency issues (Lin and Harris, 2013). Other criteria related to social justice which are of cocern are constraint of patient for finding job, study, work and et., responsibility of patient about taking care of relatives and hardness of doing activity in case of not curing. Stability and justice should be considered as one of the indicators of patients' prioritization (Chang et al., 2018). Prolonged treatment not only reduces the effectiveness of treatment but also makes the patient's condition more acute and irreversible (Globerman et al., 2013). For this reason, the effects of treatment delay were also fully considered.

\section{CONCLUSION}

The resource allocation planning is extremely challenging in healthcare systems. Especially in these systems that poor decisions may lead to chronic situations for patients. In this research, a comprehensive combined method, including discrete-event simulation, fuzzyDelphi, fuzzy-ANP, and finally, fuzzy-TOPSIS, is used to prioritize patients. 
To consider all the criteria of patient prioritization, the concluded criteria are screened using the fuzzy-Delphi method and experts' opinions. In addition to weighting and fuzzy ranking methods, results of prioritization patterns and all their details can be exported from the output of the simulation system. The results show good performance of the proposed method in the analysis and optimization of the system. The major focus of this research is patient prioritization with multiple criteria in a fuzzy environment. After collecting the information and processing by ED software, the model is simulated to include the system complexities in the model. After assuring the model validity, the priority model runs on the simulated model. The results show that the proposed model can modify patient entry based on multiple criteria in terms of productivity and social justice in the patient queuing strategy.

The contribution of this research is threefold: the literature has been reviewed to conclude the criteria concerning decisions around ICUs, the concluded criteria filtered through an expert panel which can be relied based on the method, a real application of the steps proposed is presented which allows comparing the accuracy and efficiency of the decisions made in the hospitals.

A drawback of this research can be in states of emergency which limits the options at hand and the criteria proposed may set a drawback on the aim of the study. This can be explained in the sense that this study aimed to develop a method to systemize the decision process and the method is the main contribution of the study since the authors are experts of operational management.

Future research may lie in: investigating modern methods of weighting and prioritizing in the human queue, using the queues theory and modeling in the bed dedication considering the fuzzy-MCDM methods, and investigating the hidden risks of human queues prioritization.

\section{REFERENCES}

Abbasgholizadeh Rahimi, S., Jamshidi, A., Ruiz, A. et al. (2016), "A new dynamic integrated framework for surgical patients' prioritization considering risks and uncertainties", Decision Support Systems, Vol. 88, pp. 112-20. https://doi.org/10.1016/j.dss.2016.06.003.

Adhikari, N.K.J., Fowler, R.A., Bhagwanjee, S. et al. (2010), "Critical care and the global burden of critical illness in adults", Lancet, Vol. 376, No. 9749, pp. 1339-46. https://doi.org/10.1016/S0140-6736(10)60446-1.

Ahsan, K.B., Alam, M.R., Morel, D.G. et al. (2019), "Emergency department resource optimisation for improved performance: a review", Journal of Industrial Engineering International, Vol. 15, No. 1, pp. 253-66. http://dx.doi.org/10.1007/s40092-019-00335-x.

Alexander, M., MacLaren, A., O'Gorman, K. et al. (2012), "Priority queues: where social justice and equity collide", Tourism Management, Vol. 33, No. 4, pp. 875-84. https://doi.org/10.1016/j.tourman.2011.09.009.

Allepuz, A., Espallargues, M. and Martínez, O. (2009), "Criterios para priorizar a pacientes en lista de espera para procedimientos quirúrgicos en el Sistema Nacional de Salud", Revista de Calidad Asistencial, Vol. 24, No. 5, pp. 185-91.

Al-Refaie, A. and Li, M. (2011), "Optimizing the performance of plastic injection molding using weighted additive model in goal programming", International Journal of Fuzzy System Applications, Vol. 1, No. 2 , pp. 43-54. http://dx.doi.org/10.4018/ijfsa.2011040104.

Bailey, N.T.J. (1952), "A study of queues and appointment systems in hospital out-patient departments, with special reference to waiting-times", Journal of the Royal Statistical Society. Series B. Methodological, Vol. 14, No. 2, pp. 185-99. http://www.jstor.org/stable/2983867.

Bouzon, M., Govindan, K., Rodriguez, C.M.T. et al. (2016), "Identification and analysis of reverse logistics barriers using fuzzy Delphi method and AHP", Resources, Conservation and Recycling, Vol. 108, pp. 18297. https://doi.org/10.1016/j.resconrec.2015.05.021.

Chalgham, M., Khatrouch, I., Masmoudi, M. et al. (2019), "Inpatient admission management using multiple criteria decision-making methods", Operations Research for Health Care, Vol. 23, pp. 100173. https://doi.org/10.1016/j.orhc.2018.10.001.

Chang, P.L., Hsu, C.W. and Chang, P.C. (2011), "Fuzzy Delphi method for evaluating hydrogen production technologies", International Journal of Hydrogen Energy, Vol. 36, No. 21, pp. 14172-9. http://dx.doi.org/10.1016/j.ijhydene.2011.05.045. 
Chung, C.A. (2003), Simulation Modeling Handbook: A Practical Approach, CRC Press, Boca Raton.

Creemers, S., \& Lambrecht, M. (2007). “Modeling a healthcare system as a queueing network: the case of a Belgian Hospital", SSRN Electronic Journal, pp. 1-44.

Creemers, S., Beliën, J. and Lambrecht, M. (2012), "The optimal allocation of server time slots over different classes of patients", European Journal of Operational Research. http://dx.doi.org/10.1016/j.ejor.2011.10.045.

Curtis, J.R. and Vincent, J.-L. (2010), "Ethics and end-of-life care for adults in the intensive care unit", Lancet, Vol. 376, No. 9749, pp. 1347-53. https://doi.org/10.1016/S0140-6736(10)60143-2.

Dehli, T., Fredriksen, K., Osbakk, S.A. et al. (2011), "Evaluation of a university hospital trauma team activation protocol", Scandinavian Journal of Trauma, Resuscitation and Emergency Medicine, Vol. 19, No. 1, pp. 18. https://doi.org/10.1186/1757-7241-19-18.

Fraser, G., Harrison, A. and Derrett, S. (1993). Wating Lists and Waiting Times: Their Nature and Management - A report, National Advisory Committee on Core Health and Disability Support Services, New Zealand.

Gilboy, N., Tanabe, P. and Travers, D.A. (2005), "The emergency severity index version 4: changes to ESI Level 1 and pediatric fever criteria", Journal of Emergency Nursing: JEN, Vol. 31, No. 4, pp. 357-62. http://dx.doi.org/10.1016/j.jen.2005.05.011.

Globerman, S., Esmail, N., Day, B. et al. (2013), "Reducing Wait Times for Health Care: What Canada Can Learn from Theory and International Experience", Fraser Institute, Vancouver, available at: https://ssrn.com/abstract=2337594 (accessed 22 May 2020).

Green, L.V., Soares, J., Giglio, J.F. et al. (2006), "Using queueing theory to increase the effectiveness of emergency department provider staffing", Academic Emergency Medicine, Vol. 13, No. 1, pp. 61-8. http://dx.doi.org/10.1197/j.aem.2005.07.034.

Hassin, R., Puerto, J. and Fernández, F.R. (2009), "The use of relative priorities in optimizing the performance of a queueing system", European Journal of Operational Research, Vol. 193, No. 2, pp. 476-83. https://doi.org/10.1016/j.ejor.2007.11.058.

Haviv, M., \& van der Wal, J. (2007). Waiting times in queues with relative priorities. Operations Research Letters, Vol. 35, No. 5, pp. 591-4. https://doi.org/10.1016/j.orl.2006.10.003.

Hsieh, T.-Y., Lu, S.-T. and Tzeng, G.-H. (2004), "Fuzzy MCDM approach for planning and design tenders selection in public office buildings", International Journal of Project Management, Vol. 22, No. 7, pp. 573-84. https://doi.org/10.1016/j.ijproman.2004.01.002.

Hsu, Y.L., Lee, C.H. and Kreng, V.B. (2010), "The application of Fuzzy Delphi Method and Fuzzy AHP in lubricant regenerative technology selection", Expert Systems with Applications, Vol. 37, No. 1, pp. 41925. http://dx.doi.org/10.1016/j.eswa.2009.05.068.

Huang, Q., Thind, A., Dreyer, J.F. et al. (2010), "The impact of delays to admission from the emergency department on inpatient outcomes", BMC Emergency Medicine, Vol. 10, No. 1, pp. 16. http://dx.doi.org/10.1186/1471-227X-10-16.

Jacobson, S.H., Hall, S.N. and Swisher, J.R. (2006). “Discrete-event simulation of health care systems bt patient flow: reducing delay in healthcare delivery", in Hall, R.W. (Ed.), Patient Flow: Reducing Delay in Healthcare Delivery. International Series in Operations Research \& Management Science, Springer, USA, pp. 211-52. https://doi.org/10.1007/978-0-387-33636-7_8.

Jahanshahloo, G.R., Lotfi, F.H. and Izadikhah, M. (2006), "An algorithmic method to extend TOPSIS for decision-making problems with interval data", Applied Mathematics and Computation, Vol. 175, No. 2, pp. 1375-84. https://doi.org/10.1016/j.amc.2005.08.048.

Lehmann, R., Brounts, L., Lesperance, K. et al. (2009), "A simplified set of trauma triage criteria to safely reduce overtriage: a prospective study", Archives of Surgery, Vol. 144, No. 9, pp. 853-8.

Lin, C.S. and Harris, S.L. (2013), "A unified framework for the prioritization of organ transplant patients: analytic hierarchy process, sensitivity and multifactor robustness study", Journal of Multi-Criteria Decision Analysis, Vol. 20, No. 3-4, pp. 157-72. http://dx.doi.org/10.1002/mcda.1480.

Louriz, M., Abidi, K., Akkaoui, M. et al. (2012), "Determinants and outcomes associated with decisions to deny or to delay intensive care unit admission in Morocco", Intensive Care Medicine, Vol. 38, No. 5, pp. 830-7. http://dx.doi.org/10.1007/s00134-012-2517-0.

MacCormick, A.D., Collecutt, W.G. and Parry, B.R. (2003). Prioritizing patients for elective surgery: A systematic review. In ANZ Journal of Surgery, Vol. 73, No. 8, pp. 633-42. https://doi.org/10.1046/j.14452197.2003.02605.x 
Mery, E. and Kahn, J.M. (2013), "Does space make waste? The influence of ICU bed capacity on admission decisions", Critical Care (London, England), Vol. 17, No. 3, pp. 315. http://dx.doi.org/10.1186/cc12688.

Mullins, P.M. and Pines, J.M. (2014), "National ED crowding and hospital quality: results from the 2013 Hospital Compare data", The American Journal of Emergency Medicine, Vol. 32, No. 6, pp. 634-9. https://doi.org/10.1016/j.ajem.2014.02.008.

Pegoraro, F., Portela Santos, E.A., de Freitas Rocha Loures, E. et al. (2020), "A hybrid model to support decision making in emergency department management", Knowledge-Based Systems, Vol. 203, pp. 106148. https://doi.org/10.1016/j.knosys.2020.106148

Richardson, J.D., Franklin, G., Santos, A. et al. (2009), "Effective triage can ameliorate the deleterious effects of delayed transfer of trauma patients from the emergency department to the ICU", Journal of the American College of Surgeons, Vol. 208, No. 5, pp. 671-8. https://doi.org/10.1016/j.jamcollsurg.2008.11.018.

Sadegh-Zadeh, K. (2015). Handbook of Analytic Philosophy of Medicine, Springer, USA, Philosophy and Medicine, Vol. 113. https://doi.org/10.1007/978-94-017-9579-1.

Sampietro-Colom, L., Espallargues, M., Rodríguez, E. et al. (2008), "Wide social participation in prioritizing patients on waiting lists for joint replacement: a conjoint analysis", Medical Decision Making, Vol. 28, No. 4, pp. 554-66. http://dx.doi.org/10.1177/0272989X08315235.

Singer, M. and Donoso, P. (2008), "Assessing an ambulance service with queuing theory", Computers \& Operations Research, Vol. 35, No. 8, pp. 2549-60. https://doi.org/10.1016/j.cor.2006.12.005.

Sprung, C.L., Danis, M., lapichino, G. et al. (2013), "Triage of intensive care patients: identifying agreement and controversy", Intensive Care Medicine, Vol. 39, No. 11, pp. 1916-24. http://dx.doi.org/10.1007/s00134-0133033-6.

Sun, R., Hu, J., Zhou, J., \& Chen, X. (2018), "A hesitant fuzzy linguistic projection-based MABAC method for patients"', Prioritization., Vol. 20, No. 7, pp. 2144-60. http://dx.doi.org/10.1007/s40815-017-0345-7.

Uygun, Ö., Kaçamak, H. and Kahraman, Ü.A. (2015), "An integrated DEMATEL and Fuzzy ANP techniques for evaluation and selection of outsourcing provider for a telecommunication company", Computers \& Industrial Engineering, Vol. 86, pp. 137-46. https://doi.org/10.1016/j.cie.2014.09.014.

Viswanadham, N. and Narahari, Y. (2001), "Queueing network modelling and lead time compression of pharmaceutical drug development", International Journal of Production Research, Vol. 39, No. 2, pp. 395-412. http://dx.doi.org/10.1080/00207540010004304.

Wang, L., Zhang, H.Y., Wang, J.Q. et al. (2018), "Picture fuzzy normalized projection-based VIKOR method for the risk evaluation of construction project", Applied Soft Computing, Vol. 64, pp. 216-26.

Young, T., Eatock, J., Jahangirian, M. et al. (2009). “Three critical challenges for modeling and simulation in healthcare", Proceedings of the 2009 Winter Simulation Conference (WSC), IEEE, USA, pp. 1823-30. https://doi.org/10.1109/WSC.2009.5429186.

Zadeh, L.A. (1965), "Fuzzy sets", Information and Control, Vol. 8, No. 3, pp. 338-53. https://doi.org/10.1016/S00199958(65)90241-X.

Zhou, L., Geng, N., Jiang, Z. et al. (2018), "Multi-objective capacity allocation of hospital wards combining revenue and equity", Omega, Vol. 81, pp. 220-33. https://doi.org/10.1016/j.omega.2017.11.005.

Author contributions: Afsaneh Davodabadi: Writing. In the other activities (such as data collection, managing the project, etc.), all the authors contributed equally. 